УДК 532.135

DOI: $18.101 / 2306-2363-2019-2-3-12-19$

\title{
УГЛЕПЛАСТИКИ: ТЕХНОЛОГИЯ ПОЛУЧЕНИЯ И ОПРЕДЕЛЕНИЕ МЕХАНИЧЕСКИХ ХАРАКТЕРИСТИК
}

\section{(C) В. Н. Манхиров}

аспирант,

Институт физического материаловедения СО РАН

670031, Улан-Удэ, ул. Сахьяновой, 6

E-mail: mankhrov93@mail.ru

\section{(C) А. В. Номоев}

доктор физико-математических наук,

заведующий лабораторией физики композитных материалов,

Институт физического материаловедения СО РАН

670031, Улан-Удэ, ул. Сахьяновой, 6

E-mail: nomoevav@mail.ru

\section{(C) В. В. Сызранцев}

кандидат физико-математических наук, заместитель директора по научной работе,

Институт физического материаловедения СО РАН

670031, Улан-Удэ, ул. Сахьяновой, 6

\section{() О. Ж. Аюрова}

кандидат технических наук,

научный сотрудник,

Байкальский институт природопользования СО РАН

670031, Улан-Удэ, ул. Сахьяновой, 6

E-mail: chem88@mail.ru

Изготовлены образцы углепластика по технологии вакуумной инфузии и проведены эксперименты по определению его механических свойств. Образцы изготовлены из карбонового полотна, пропитанного эпоксидной смолой. Рассчитаны геометрические размеры образцов для испытания на прочность при растяжении, сжатии, измерен модуль Юнга в соответствии с ГОСТом для проведения механических испытаний композитных полимеров. Экспериментально определены механические свойства углепластика и проведен анализ полученных результатов.

Ключевые слова: углепластик; карбон; эпоксидный полимер; модуль Юнга; прочность на сжатие; вакуумная инфузия; наноразмерные частицы.

\section{Для цитирования}

Манхиров В. Н., Номоев А. В., Сызранцев В. В., Аюрова О. Ж. Углепластики: технология получения и определение механических характеристик // Вестник Бурятского государственного университета. Химия. Физика. 2019. Вып. 2-3. С. 13-21.

Углепластики на основе карбоновых волокон обладают уникальными механическими свойствами и находят применение во многих отраслях промышленности. Кроме этого, изделия из углепластика отличаются длительным сроком 
В. Н. Манхиров, А. В. Номоев, В. В. Сызранцев, О. Ж. Аюрова. Углепластики: технология получения и определение механических характеристик

эксплуатации $[1,2]$. Основой углепластика (карбона) являются нити углерода, из которых плетется карбоновое полотно разного рисунка. Для придания материалу объемной твердой формы слои полотна соединяются между собой с помощью эпоксидных смол. Эпоксидная смола в сочетании с полотном придает сформированным образцам такие свойства, как водостойкость, механическая прочность [3]. Достаточно короткое время отвердевания - также одно из важных свойств эпоксидных полимеров.

В последнее время для дополнительного изменения механических свойств углепластик модифицируют различными, в том числе наноразмерными добавками [4].

Целью настоящей работы являлось изготовление образцов углепластика по технологии вакуумной инфузии и проведение экспериментов по определению механических свойств углепластика.

\section{Методика эксперимента}

В настоящей работе углепластик создавался методом вакуумной инфузии. Для соединения слоев карбонового полотна использовалась эпоксидная смола ЭД 20. Для определения прочности на растяжение, сжатие, модуль Юнга углепластика использовалась универсальная машина Instron 66 - испытательное оборудование для оценки механических свойств материалов.

Эксперименты проводились по следующим последовательности и условиям:

- расчет геометрических характеристик образцов углепластика для испытания на прочность на растяжение, сжатие, модуль Юнга;

- определение минимальных размеров на испытание образцов углепластика используя характеристики Инстрона-66, ГОСТа на композитные материалы и литературные данные;

- изготовление образцов согласно расчетным параметрам;

- выявление следующих параметров для испытаний образцов на механические свойства: начальная нагрузка, скоростей растяжения и сжатия;

- обеспечение безопасности при испытаниях на прочность;

- определение: прочности на растяжение углепластика с продольным плетением волокон из углеткани с эпоксидной смолой; прочности на сжатие углепластика с поперечным плетением из углеткани с эпоксидной смолой; модуля Юнга углепластика с эпоксидной смолой для двух типов плетений.

\section{Технология изготовления углепластика (карбона)}

Ниже рассмотрены основные этапы изготовления углепластика из карбоновой ткани и эпоксидной смолы. Листы углеткани послойно накладываются друг на друга, количество слоев зависит от того, какая толщина изделия нужна (рис. 1a). На верхний слой накладывается жертвенная ткань и направляющая сетка (рис. 1б). Многослойный сэнвдич, сформированный таким образом, помещается в специальный герметичный полиэтиленовый пакет. К пакету подсоединены мембранные трубки и вакуумный насос (рис. 1в). В результате работы насоса 
происходит откачка воздуха из пакета, что обеспечивает отсутствие воздуха между слоями.
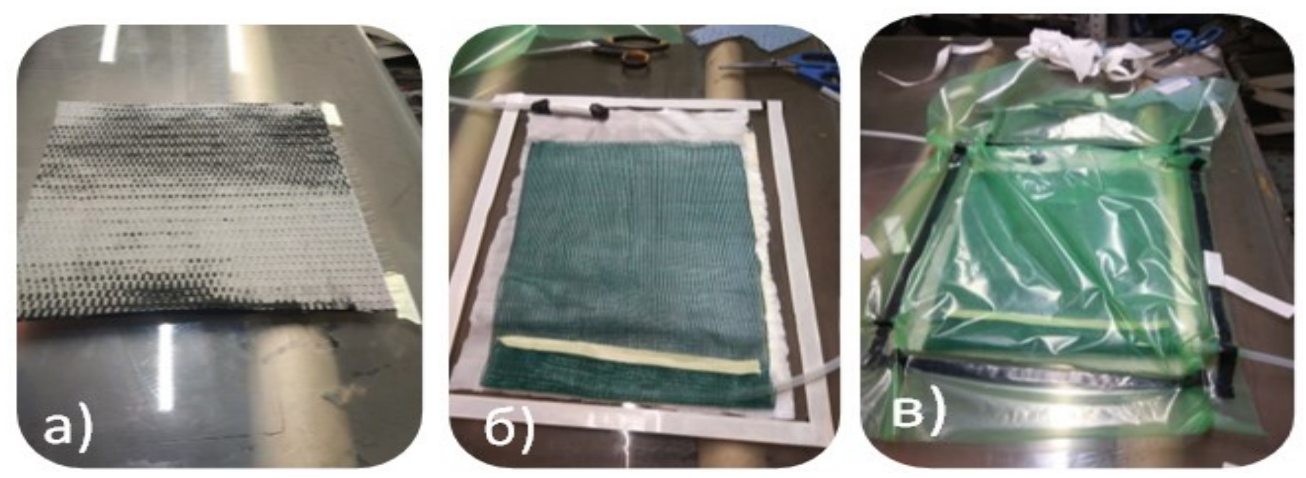

Рис. 1. Фото: а - листы углеткани; б - жертвенной ткани с направляющей сеткой, видны трубки для откачки воздуха и ввода смолы в пакет; в - листы углеткани, размещенные в герметичном полиэтиленовом пакете

Далее, через трубку в изделие вводится эпоксидная смола. После процесса полимеризации в сушильном шкафу при температуре $150^{\circ} \mathrm{C}$ создается готовое углепластиковое изделие.

\section{Результаты экспериментов и их анализ}

Для определения механических свойств на растяжение углепластиков, было изготовлено пять образцов с продольным и пять образцов с поперечным плетением (рис. 2a), имеющих одинаковые размеры, а для определения свойств на сжатие - по пять образцов с продольным плетением и такое же количество образцов с поперечным плетением, с меньшим размером (рис. 2б). Образцы поочередно фиксировались в зажимах машины Instron-66. Затем образцы проходили проверку на прочность при одинаковой начальной нагрузке $(\mathrm{F}=20 \mathrm{H})$ и скорости (v = 1 мм/мин) как при растяжении, так и при сжатии. Целостность образцов определялась визуальным способом. По данным зависимости растяжения от приложенной нагрузки вычислялся модуль Юнга образцов.

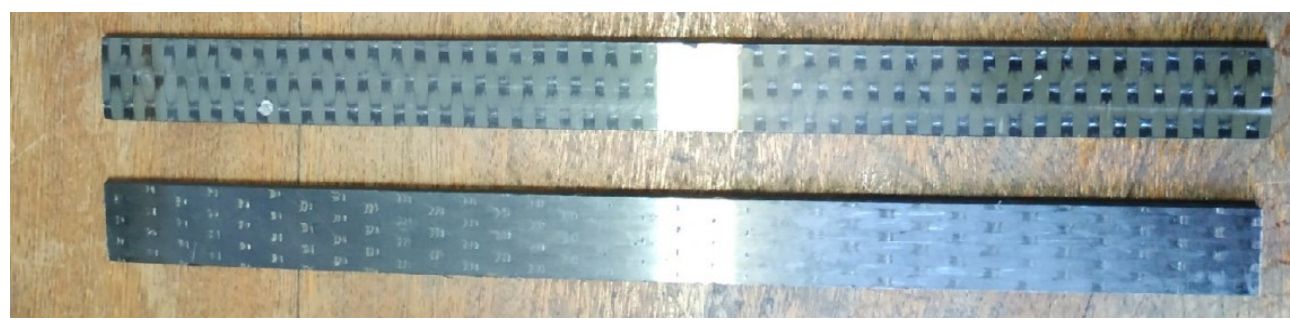

Рис. 2а. Фото образцов углепластика для экспериментов на растяжение с длиной 250 мм, шириной 20 мм, толщиной 2.3 мм (поперечное (верх) и продольное (низ) плетение).

Длина образца между зажимами $\mathrm{I}_{0}=100$ мм 
В. Н. Манхиров, А. В. Номоев, В. В. Сызранцев, О. Ж. Аюрова. Углепластики: технология получения и определение механических характеристик

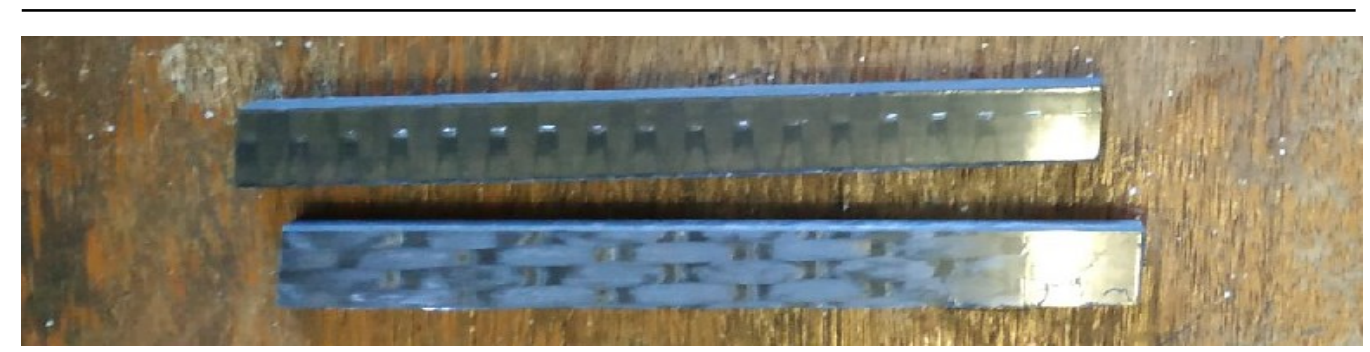

Рис. 26. Фото образцов для экспериментов на сжатие с длиной 50 мм, шириной 10 мм, толщиной 2.3 мм. Длина образца между зажимами $\mathrm{I}_{0}=50$ мм.

Вычисление модуля Юнга углепластиков с продольным плетением нитей при их растяжении.

Определялся модуль Юнга без разрушения образца с продольным плетением нитей при их растяжении - это тангенс угла наклона прямой в координатах нагрузка - перемещение (упругий модуль Юнга).

Для образцов 1-6 (рис. 3) получены следующие результаты (табл. 1).

Изменение прямо пропорциональной зависимости на кривых происходит вследствие чрезмерно большой нагрузки на траверсы (зажимы) в которых закреплены образцы высокой твердости с продольным расположением нитей ткани из карбонового волокна. Поэтому не удалось определить предел прочности на растяжение и модуль Юнга при разрушении данных образцов. Достигнутое в эксперименте максимальное значение напряжения по кривой напряжениерастяжение (рис. 3) дает значение $\sigma=30$ кН/(20·2.3 мм²) $=650$ МПа. Визуальный осмотр образцов показал, что их целостность после проведения экспериментов не была нарушена.

Таблица 1

Результаты определения модуля Юнга при растяжении

\begin{tabular}{|l|l|l|l|l|}
\hline Номер образца & $\varepsilon$, мм & $\mathrm{F}, \mathrm{H}$ & $\sigma, \mathrm{MПа}$ & E, MПа \\
\hline 1 & 0,4 & 1797 & 39,065 & 9766 \\
\hline 2 & 1 & 4767 & 103,63 & 10363 \\
\hline 3 & 1 & 4795 & 104,24 & 10424 \\
\hline 4 & 1 & 4687 & 101,89 & 10189 \\
\hline 5 & 1 & 4706 & 102,3 & 10230 \\
\hline 6 & 1 & 4132 & 89,826 & 8982,6 \\
\hline
\end{tabular}

$\mathrm{E}_{\text {среднее }}=10+0,5$ ГПа. Для сравнения: $\mathrm{E}_{\text {полистирол }}=2,1$ ГПа, $\mathrm{E}_{\text {медь }}=110$ ГПа, $\mathrm{E}_{\text {сталь }}=$ 190-210 ГПа. 
Образцы с 1 по 6
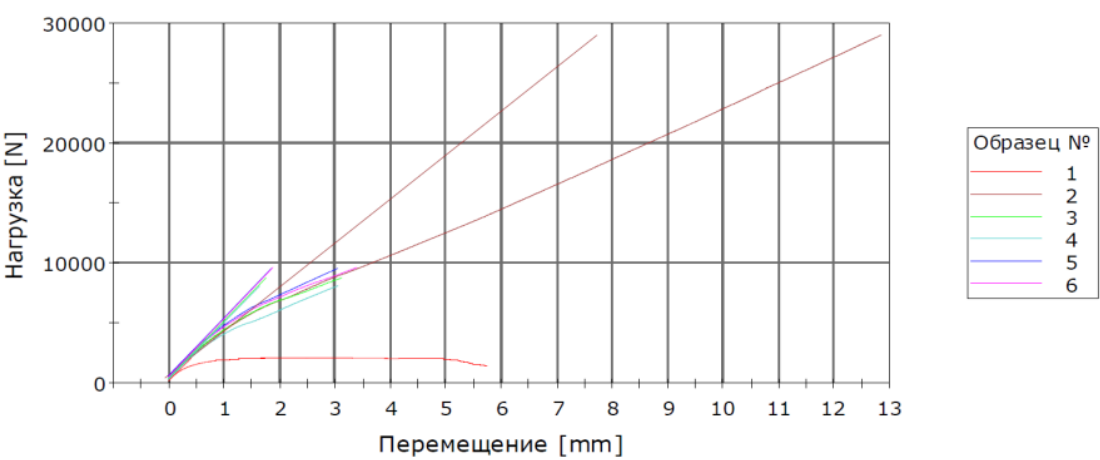

Рис. 3. Зависимость нагрузки на образцы углепластиков с продольным плетением нитей от перемещения при их растяжении.

Вычисление модуля Юнга при сжатии углепластиков с продольным плетением нитей

Определялся модуль Юнга без разрушения образца - это тангенс угла наклона прямой в координатах нагрузка - перемещение (модуль упругой области кривой. Результаты измерений представлены на рис. 4. Для образцов 1-4 получены следующие результаты (табл. 2).

Таблица 2

Результаты определения модуля Юнга при сжатии

\begin{tabular}{|c|c|c|c|c|}
\hline Номер образца & $\varepsilon, \mathrm{MM}$ & $\mathrm{F}, \mathrm{H}$ & $\sigma, \mathrm{M} а$ & $\mathrm{E}, \mathrm{M \Pi а}$ \\
\hline 1 & 0,167 & 1511 & 65,69 & 19669 \\
\hline 2 & 0,167 & 1530 & 66,52 & 19917 \\
\hline 3 & 0,167 & 1533 & 66,65 & 19956 \\
\hline 4 & 0,167 & 1519 & 66,04 & 19773 \\
\hline
\end{tabular}

$\mathrm{E}_{\text {среднее }}=19,83+0,1$ ГПа. Максимальное значение напряжения $\sigma_{\max }=182 \mathrm{MПа.}$

ГОСТ 12801-98

Образцы с 1 по 4

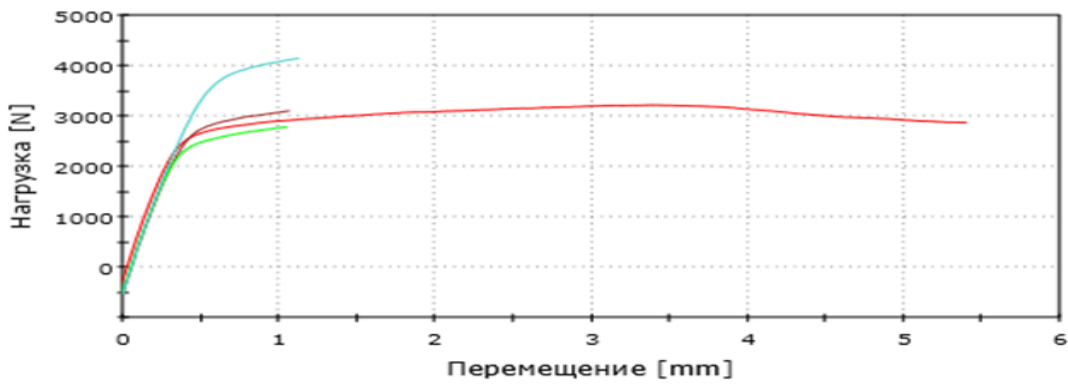

O6paseu No

Рис. 4. Зависимость нагрузки на образцы углепластиков с продольным плетением нитей при их сжатии 
В. Н. Манхиров, А. В. Номоев, В. В. Сызранцев, О. Ж. Аюрова. Углепластики: технология получения и определение механических характеристик

Определение механических свойств углепластиков при сжатии и растяжении с поперечным плетением нитей.

На рис. 5 представлены результаты по испытанию углепластиков на растяжение с поперечным плетением нитей. Для образцов 1-3 (рис.5) получены следующие результаты (табл. 3):

Таблица 3

Результаты испытаний углепластика на растяжение

\begin{tabular}{|c|c|c|c|c|}
\hline Номер образца & $\varepsilon$, мM & $\mathrm{F}, \mathrm{H}$ & $\sigma, \mathrm{M}$ Па & $\mathrm{E}, \mathrm{M \Pi а}$ \\
\hline 1 & 1 & 675 & 14,67 & 1467 \\
\hline 2 & 1 & 662 & 14,39 & 1439 \\
\hline 3 & 1 & 623 & 13,54 & 1354 \\
\hline
\end{tabular}

$\mathrm{E}_{\text {среднее }}=1,42+0,05$ ГПа

Образцы с 1 по 6

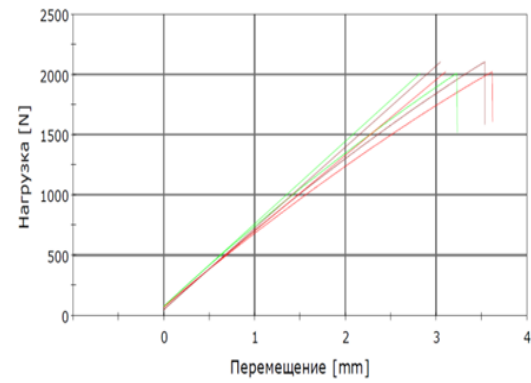

06разец N.

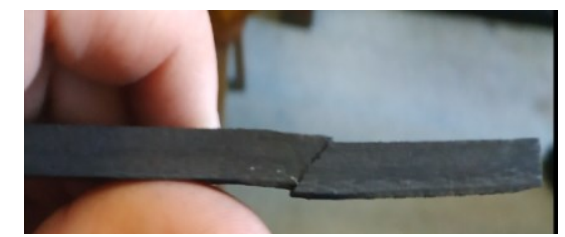

Рис. 5. а - зависимость нагрузки на образцы углепластиков с поперечным плетением нитей от перемещения при их растяжении; б - фото углепластика после разрушения

Таблица 4

Результаты испытаний углепластика на сжатие

\begin{tabular}{|c|c|c|c|c|}
\hline Номер образца & $\varepsilon$, мм & $\mathrm{F}, \mathrm{H}$ & $\sigma, \mathrm{MПа}$ & $\mathrm{E}, \mathrm{M \Pi а}$ \\
\hline 1 & 0,391 & 1002 & 43,56 & 5571 \\
\hline 2 & 0,391 & 998 & 43,39 & 5548 \\
\hline 3 & 0,391 & 1012 & 44,0 & 5627 \\
\hline 4 & 0,391 & 1028 & 44,69 & 5715 \\
\hline
\end{tabular}

$\mathrm{E}_{\text {среднее }}=5,615+0,06$ ГПа. Максимальное значение напряжения $\sigma_{\max }=210$ МПа. 

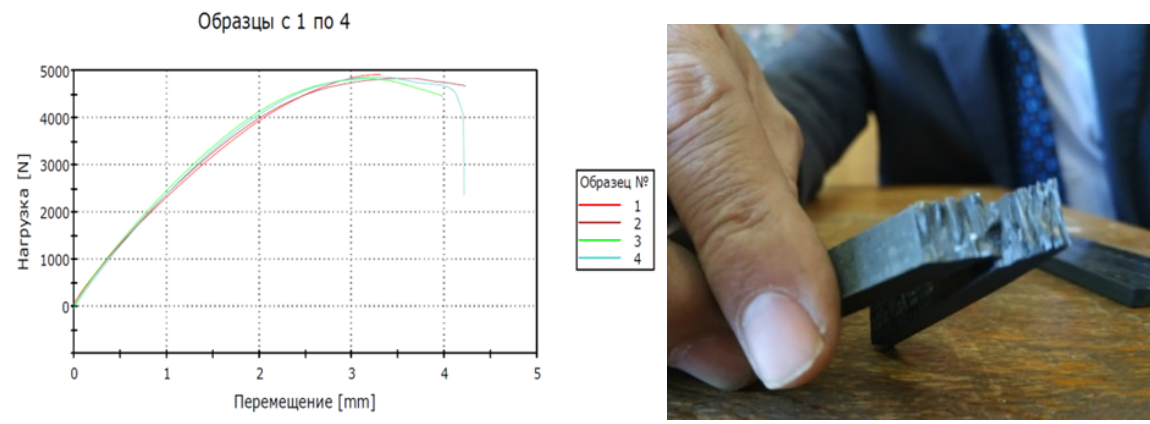

Рис. 6. а - зависимость нагрузки на образцы углепластиков с поперечным плетением нитей от перемещения при их сжатии; б - фото углепластика после разрушения.

Прочность на растяжение и на сжатие углепластиков значительно меньше, по сравнению с образцами с поперечным плетением нитей.

На рис. 6 представлены результаты по испытанию углепластиков на сжатие с поперечным плетением нитей. Для образцов 1-4 получены следующие результаты, представленные в табл. 4.

\section{Выводы}

Освоена технология изготовления углепластика методом вакуумной инфузии из карбоновой ткани с наполнением эпоксидной смолой.

Проведенные эксперименты показали, что углепластик с продольным плетением нитей обладает значительно большим модулем Юнга и прочностными характеристиками по сравнению с образцом с поперечным плетением.

Работа выполнена в рамках государственного задания Института физического материаловедения СО РАН № 01201366187.

\section{Литература}

1. Донецкий К. И., Коган Д. И., Хрульков А. В. Свойства полимерных композиционных материалов, изготовленных на основе плетеных преформ // Труды ВИАМ. 2014. 一 № 3. - С. 17-23

2. Молчанов Б. И., Гудинов М. М. Свойства углепластиков и области их применения // Авиационная промышленность. - 1997. — № 3-4. - С. 58-60.

1. Кирова Е. С., Нилов А. П. Нанопорошки из оксидов металлов. - 2014. http://sdamzavas.net/3-69746.html

2. https://studfiles.net/preview/6382292/page:2/

3. https://ustroistvo-avtomobilya.ru/e-kspluatatsionny-e-materialy/ugleplastiki/ newnano.ru/entsciklopediya/nanotehnologiya/dioksid-kremniya.html

4. https://artex-fabric.com/articles/157-st-carbon.html

5. http://recn.ru/epoksidnaya-smola-primenenie-i-svojstva 


\title{
CARBON PLASTIC: TECHNOLOGY OF PRODUCTION AND DETERMINATION OF MECHANICAL CHARACTERISTICS
}

\author{
M. N. Mankhirov \\ Postgraduate \\ Institute of Physical Materials Science SB RAS \\ E-mail: mankhrov93@mail.ru

\section{A. V. Nomoev} \\ Doctor of Physical and Mathematical Sciences \\ Head of the laboratory of Physics of Composite Materials \\ Institute of Physical Materials Science SB RAS \\ 670047, Sakhyanova 6, Ulan-Ude \\ E-mail: nomoevav@mail.ru \\ V. V. Syzrantsev \\ Candidate of Physical and Mathematical Sciences \\ Deputy Director \\ Institute of Physical Materials Science SB RAS \\ 670031, Ulan-Ude \\ E-mail:vveliga@mail.ru
}

O. Zh. Ayurova

Candidate of Technical Sciences

Research fellow

Baikal Institute of Nature Management SB RAS

Sakhyanova str., 6, Ulan-Ude, 670047

E-mail: chem88@mail.ru

Samples of carbon plastics were made using vacuum infusion technology and experiments were carried out to determine the mechanical properties of carbon plastics. Carbon plastics samples contain a carbon fiber web filled with epoxy resin. Geometrical dimensions of the samples for tensile and compressive strength tests and Young modulus in accordance with GOST to carry out mechanical tests of composite polymers were calculated. The mechanical properties of carbon plastics were experimentally determined and the obtained results were analyzed.

Keywords: carbon plastics; carbon; epoxy polymer; Young modulus; compressive strength; vacuum infusion; nanoscale particles. 